\title{
Retorno às identidades? Uma discussão dos Estudos Culturais à ideia de dispositivo em Foucault
}

\section{José Cristian Góes ${ }^{I}$}

Resumo: A proposta desse trabalho é discutir as identidades na perspectiva dos Estudos Culturais, ou seja, como fenômeno em permanente trânsito, em um ambiente instável e como alvo de intensos jogos de poder. Ocorre que esse não é um processo nítido nas superfícies cotidianas das relações sociais, emergindo mais em períodos de crises, muitas vezes de forma extremada, a exemplo do que ocorre contemporaneamente em várias regiões do planeta, passando-se a impressão de um retorno às identidades. Para aprofundar essa questão, sugerimos aproximar as identidades do dispositivo em Foucault. A contribuição desse autor possibilita ampliar a reflexão sobre o trânsito paradoxal das identidades, de forma a perceber as tentativas de sua sedimentação, mas esse mesmo percurso guarda forças, às vezes silenciosas, para fissuras e rupturas.

Palavras-chave: Identidades. Estudos Culturais. Dispositivo. Foucault.

\section{Return to identities? A discussion on Cultural Studies to the conception of dispositive in} Foucault's work

Abstract: The purpose of this paper is to discuss identities from the perspective of Cultural Studies, i.e., to discuss them as a phenomenon in continuous transit, in an unstable environment and as a target of fierce power games. It turns out that this is not a clear process in social relations' everyday surfaces, emerging frequently in times of crisis, many times in extreme terms, similar to what simultaneously occurs in several regions of the planet, and giving the impression of a return to identities. To further explore this issue, we suggest approaching identities to the conception of device in Foucault's work. This author's contribution makes it possible to expand the reflection on the paradoxical transit of identities in order to realize the attempts of its sedimentation, but this same route saves strength, sometimes silent, for fissures and breaks.

Keywords: Identities. Cultural Studies. Device. Foucault.

Artigo recebido em 21/03/2016 e aprovado em 07/04/2016. 


\section{JOSÉ CRISTIAN GÓES}

\section{Para começar: delimitando o campo}

Estamos tão profundamente mergulhados no mundo da vida que inúmeros e complexos processos sociais que nos constituem parecem ser como simples atitudes naturais, diluídas no intenso cotidiano. Longe das percepções ordinárias, esses processos nos atravessam quase que completamente despercebidos. Um deles é o das identidades, um fenômeno fundamental aos sujeitos e às sociedades porque produz uma sensação de reconhecimento, configurando o nós, e, ao mesmo tempo, marcando imaginárias diferenças de outros. Sugerimos, assim, pensar as identidades como ligas seletivas que agem para nos aproximar por sensações de pertença, que parecem nos fixar num mundo organizado, mas também por uma fabricação da diferença de um outro que não o reconhecemos como membro do grupo a que pertencemos.

Existem vários ângulos para tratar das identidades, indo da psicologia até a lingüística. Nesse trabalho, abraçamos uma perspectiva apresentada pelas ciências sociais, especialmente a partir dos chamados Estudos Culturais. Dessa forma, de saída, já pontuamos as identidades como processo, como construção social em fluxo, ou seja, essa concepção sepulta à ideia que esse fenômeno é um algo dado, fixo, natural, herdado e registrado em certidão de nascimento. Os Estudos Culturais discutem as identidades como um meio fabular e instável, ou seja, condições que garantem fragilidade e abertura para reconfigurações sempre inacabadas. As identidades são nomeadas no plural porque são muitas, estão em processo e sob rasura, assim rejeitando-se ideias pré-concebidas, dadas e imutáveis, conforme Stuart Hall ${ }^{\mathrm{II}}$.

Depois de apresentadas algumas formulações iniciais sobre as identidades, sugerimos avançar no sentido de refletir sobre os processos que podem estar no centro das configurações sociais desse fenômeno. De fato, as identidades não fazem parte das agendas, mas quando surgem no cotidiano parecem reafirmar, reforçar, retornar às marcas, heranças, tradições e até justificativas genéticas que são usadas, principalmente, no sentido de fixar o outro, o diferente, o estranho, o estrangeiro.

Entendemos assim que as identidades não são em si identificações e diferenciações, mas um mecanismo, um dispositivo político que é acionado em razão de intensas e sutis relações de poder para reduzir e enquadrar indivíduos e grupos. Em outras palavras, as identidades são meio, e não um fim em si. Essa abordagem fica mais clara ao recorremos às ideias sobre o dispositivo em Michel Foucault, e que veremos adiante.

O entrelaçamento entre identidades e dispositivo é o objetivo desse trabalho de reflexão teórica, o que pode nos ajudar a pensar às configurações contemporâneas e globalizantes das identidades, percebendo-as como um fenômeno profundamente paradoxal. Contudo, em razão de sua condição aberta e instável, esse ambiente pode sempre apontar para fissuras e rupturas.

\section{Aprofundado as identidades}

Os Estudos Culturais gestados no Centre for Contemporary Cultural Studies, da Universidade de Birminghan, a partir de 1964, são um ambiente fecundo para pensar as identidades. Através desses, elas navegam com fluidez porque a cultura, base de tais estudos, 


\title{
JOSÉ CRISTIAN GÓES
}

não é entendida como algo rígido, monolítico, mas como um fenômeno que emerge em contínua construção, uma experiência viva e não um algo dado. Ou seja, a cultura é um processo que abriga as relações de forças sociais em tensão constante entre a tradição e a ruptura. Nos Estudos Culturais, por exemplo, existem reflexões sobre nacionalismo, póscolonialismo, multiculturalismo, boa parte delas associadas às identidades.

Hall $^{\mathrm{III}}$ diz que as identidades não são naturais e fixas, mas a "celebração do móvel". Também explica Manuel Castells ${ }^{\mathrm{IV}}$ que elas, mesmo tendo a origem em instituições dominantes, só vão se converter como identidades "se os atores sociais as interiorizam e constroem seu sentido em torno dessa interiorização". Neste estudo, nossa atenção volta-se às identidades culturais e, de modo especial, às nacionais, que são "fonte de sentido e experiência para as pessoas", na afirmação de Castells ${ }^{\mathrm{V}}$.

É fundamental pontuar que a noção de processo das identidades é uma construção contemporânea, datada do final do século XX e início do XXI. Lembra Hall ${ }^{\mathrm{VI}}$ que as identidades "nascem" com a Modernidade, fabricadas para orientar os sujeitos na "Idade das Luzes". Boaventura de Sousa Santos ${ }^{\mathrm{VII}}$ chega a afirmar que a Era Moderna nasce com e das identidades na medida em que elas revelam a individualidade ao homem e confirmam o "colapso da cosmovisão teocrática medieval". Para Anthony Giddens VIII, a "Modernidade" é um grande conjunto de "instituições e modos de comportamento estabelecidos pela primeira vez na Europa depois do feudalismo".

De fato, antes do século XVI, a vida dos homens, de maneira geral, apoiava-se nas estruturas e tradições divinas. A sua identificação terrena era determinada pelos desígnios celestiais, e as mudanças eram imperceptíveis e extremamente controladas. Entretanto, na primeira metade do século XVI, muitos movimentos iniciam um rompimento desse quadro. Segundo Hall.

\begin{abstract}
A Reforma e o Protestantismo, que libertaram a consciência individual das instituições religiosas da Igreja e a expuseram diretamente aos olhos de Deus; o Humanismo Renascentista, que colocou o Homem ( revoluções científicas, que conferiram ao Homem a faculdade e as capacidades para inquirir, investigar e decifrar os mistérios da Natureza; e o Iluminismo, centrado na imagem do Homem racional, científico, libertado do dogma e da intolerância, e diante do qual se estendia a totalidade da história humana, para ser compreendida e dominada ${ }^{\mathrm{IX}}$.
\end{abstract}

Assim, a Era Moderna faz emergir o homem-indivíduo, ou o reconhecimento da subjetividade. O "indivíduo" é a resposta às ruínas do sistema feudal. O homem Moderno é portador de identidade, está no centro, unificado, dotado de marcas genéticas ao nascer e que lhe as identificariam para sempre, ultrapassando gerações. Um reflexo desse processo, já nos séculos XIX e XX, é a consolidação das ideias de nacionalidade e de nação, que vão se constituir, como lembra Edward Said $^{X}$, no "núcleo do pensamento cultural na era do imperialismo". Para Giddens ${ }^{\mathrm{XI}}$, das várias estruturas sociais criadas na Modernidade, "a mais importante é o estado-nação". E é nessa esteira que as identidades culturais são inventadas como uma das formas de legitimar os estados nascentes, as suas frontreiras, os nacionais e os de fora. 


\section{JOSÉ CRISTIAN GÓES}

Mas assim como Anderson ${ }^{\mathrm{XII}}$, Giddens, Hall, Castells, também Eric Hobsbawm ${ }^{\mathrm{XIII}}$ alerta que até a identificação nacional, surgida com e na Modernidade, não é um porto seguro; ela "pode mudar e deslocar-se no tempo, mesmo em períodos muito curtos". Também ensina Etienne Balibar XIV que a "ilusão" sobre nações e identidades tem dupla dimensão: a de que os territórios são mais estáveis, com dominação mais ou menos unívoca; e de que a evolução tem um longo passado que caminha ao inevitável futuro. "Projeto e destino são duas figuras simétricas da ilusão da identidade nacional", conforme Balibar ${ }^{\mathrm{XV}}$.

Ou seja, como reforça Said ${ }^{X V I}$ : “a identidade não implica em estabilidade dada e eternamente determinada, nem uma exclusividade, um caráter irredutível ou um estatuto privilegiado como algo total e completo em si e sobre si mesmo". Até mesmo identidades "como a de mulher, homem, país africano [...] escondem negociações de sentido, jogos de polissemia, choques de temporalidades em constante processo de transformações", segundo

Sousa Santos ${ }^{\text {XVII }}$. Ou ainda, como afirma Zygmunt Bauman ${ }^{\text {XVIII }}$, que "o 'pertencimento' e a 'identidade' não têm a solidez de uma rocha, não são garantidos para toda a vida, são bastante negociáveis e renegociáveis".

\section{Globalização: fim e retorno das identidades ao mesmo tempo}

A partir da segunda metade do século XX, com o avanço da ideia de globalização, há um "descentramento" dos indivíduos, momento em que se perceber com mais nitidez as identidades em jogo, em transição. Porém, as fragmentações dos sujeitos e das estruturas sociais denunciam que "somos confrontados por uma multiplicidade desconcertante e cambiante de identidades possíveis, com cada uma das quais poderíamos nos identificar - ao menos temporariamente", no dizer de Hall $^{\mathrm{XIX}}$. Essas posições dialogam com Bhabha ${ }^{\mathrm{XX}}$, isto é, que "a identidade nunca é um a priori, nem um produto acabado; ela é apenas e sempre o processo problemático de acesso a uma imagem de totalidade". Com a globalização, com a redução da ideia de tempo e espaço, com a imaginária "aldeia global", as identidades marcardas pela fixadez - parecem perder sentido. O homem circula pelo mundo, parece não haver mais fronteiras.

No entanto, esse processo não é simples assim e não se confirma nessa perspectiva. De fato, as identidades assumem uma dinâmica provisória e imaginária, mas é preciso deixar explícito que elas sofrem ações de poder para sedimentação, fixação e estabilidade, principalmente na invenção do outro, o que acaba prevalecendo. De forma que, refletir sobre identidades como um fenômeno aberto e em fluxo não significa imaginar um percurso sem rumo, ao sabor de desejos. Ou seja, estamos diante da "impossibilidade de reivindicar uma origem para o Eu (e o Outro)", no dizer de Bhabha ${ }^{\mathrm{XXI}}$, superando uma lógica que busca enxergar a identidade como se fosse representação que satisfaz o objeto, mantendo-se determinismos e unicidades. É preciso se reconhecer esse movimento, uma experiência conturbada que se dá no atravessar, uma travessia em meio a disputas, movida por relações de poder. $\mathrm{E}$ as identidades emergem no interior desses jogos. 


\title{
JOSÉ CRISTIAN GÓES
}

Ou seja, reforçamos que a imagem categórica de uma identidade natural, determinada, fixa, marcada na diferença de um outro e fabricada na Era Moderna, porém com traços nas muralhas medievais, não se perdeu no tempo e mem foi superada pelos "descentramentos" da globalização. Ao contrário, o mundo descentrado produz sujeitos confusos, sem certezas, sem amarras identitárias que lhe garantam sensação de segurança. Quanto mais se intensificam esses efeitos, deixando opacas e frouxas fronteiras e imaginando um cidadão-mundo despregado, mais são dadas respostas identitárias do "retorno" à sensação de amparo identitário. São respostas com amplos apelos políticos, econômicos, culturais, religiosos e que contradizem à lógica do modelo global. O jornalismo contemporâneo, por exemplo, revela inúmeros e crescentes casos de xenofobia, de lutas separatistas, de massacres étnico-raciais, de perseguições religiosas, de diásporas, que têm como conteúdo central e motivador a idei de retorno às identidades mesmas.

$\mathrm{Na}$ medida em que a globalização promete o "fim das fronteiras" é incontornável o intenso encontro entre os centros e as periferias. Para Hall

\begin{abstract}
Após a Segunda Guerra Mundial, as potências europeias descolonizadoras pensaram que podiam simplesmente cair fora de suas esferas coloniais de influência, deixando as consequências do imperialismo atrás delas. Mas a interdependência global agora atua em ambos os sentidos. O movimento para fora (de mercadorias, de imagens, de estilos ocidentais e de identidades consumistas) tem uma correspondência num enorme movimento de pessoas das periferias para o centro [...]. Impulsionada pela pobreza, pela seca, pela fome, [...] pela dívida externa acumulada de seus governos para com os bancos ocidentais, as pessoas mais pobres do globo, em grande número, acabam por acreditar na 'mensagem' do consumismo global e se mudam para os locais de onde vêm os 'bens' e onde as chances de sobrevivência são maiores ${ }^{\text {XII }}$.
\end{abstract}

Reforçamos que nossa abordagem reconhece as identidades como construções sociais móveis e instáveis e, estando em permanente tensão. Há forças que as impulsionam para a fixidez e a estabilidade, e é esse jogo incessante tentar cravar uma identidade, fazendo-se imaginá-la como natural e gerando unidade em torno mais do outro do que do nós. Porém, de outro lado, estamos em campo aberto e que se reconhece em trânsito, inconstante, de várias identidades. "Se sentimos que temos uma identidade unificada desde o nascimento até a morte é apenas porque construímos uma cômoda estória sobre nós mesmos ou uma confortadora narrativa do eu", segundo Hall ${ }^{\mathrm{XXIII}}$ [grifo nosso].

Não obstante esse período de celebração das incertezas, "modernidade tardia", "pósmodernidade" ou "época líquido-moderna", no dizer de Bauman ${ }^{\mathrm{XIV}}$, as maiores forças políticas hegemônicas continuam a reforçar as identidades como naturais e imutáveis porque isso atende a uma série de interesses políticos e econômicos. Por isso, Said ${ }^{\mathrm{XXV}}$ alerta que, durante as relações e os contatos entre os europeus e os outros, há mais de 500 anos, "a única ideia que quase não variou foi a de que existe um 'nós' e um 'eles', cada qual muito bem definido, claro, intocavelmente autoevidente", conforme Said $^{\mathrm{XXVI}}$. Como bem lembra Bauman XXVII: "O campo de batalha é o lar natural da identidade".

Ao refletir sobre a globalização, Milton Santos ${ }^{\text {XVIII }}$ defende a tese que esse processo é reversível, apesar da lógica do capital propagandear o contrário. Para esse autor, a mesma força 


\section{JOSÉ CRISTIAN GÓES}

que constrói "um mundo confuso e perverso, pode vir a ser uma condição da construção de um mundo mais humano", segundo Santos ${ }^{\text {XIX }}$. No entanto, ele aposta que essas transformações não virão dos centros, mas das margens. "Na Ásia, na África e mesmo na América Latina, a vida local se manifesta ao mesmo tempo como uma resposta e uma reação a essa globalização", de acordo com Santos ${ }^{X X X}$. Sua justificativa é que "gente junta cria cultura" e produz uma vizinhança que valoriza "a experiência da escassez e a experiência da convivência e da solidariedade", para Santos ${ }^{\text {XXI }}$. Sousa Santos também festeja as culturas de fronteira porque elas alimentam-se dos fluxos que as atravessam. "É uma porta de vai-e-vem, e como tal nunca está escancarada, nem nunca está fechada", para Sousa Santos ${ }^{\text {XXII. }}$.

\section{A construção do dispositivo identitário}

Depois desse percurso, recorremos agora à ideia de dispositivo em Foucault, em razão dela auxiliar ao que podemos chamar de papel das identidades na contemporaneidade, não como um retorno, mas como um meio para perceber os jogos de poder em sua constituição. Partilhamos do entendimento que o dispositivo é um conjunto complexo, amplo e heterogêneo de elementos que abraça uma série de "discursos, instituições, organizações arquitetônicas, decisões regulamentares, leis, medidas administrativas, enunciados científicos, proposições filosóficas, morais, filantrópicas", no conceito de Foucault ${ }^{\text {XXXIII }}$. Para ele, o dispositivo tem uma condição fundamental: está em incessante jogo de poder, entrecortado em todas as direções por diversas linhas força. É um emaranhado de discursos e instituições que se articulam e se movem em razão das relações sociais, das disputas de poder.

Ocorre que Foucault XXXIV esclarece que esse "poder" em meio ao dispositivo não se apresenta de forma nítida. Ele se disfarça para ser, estrategicamente, aceito como se fosse natural do processo, ou seja, "é somente mascarando uma parte importante de si mesmo que o poder é tolerável. Seu sucesso está na proporção daquilo que consegue ocultar dentre seus mecanismos", afirma Foucault XXXV.

Importante ressaltar que o dispositivo possui, além dessa centralidade do poder, algumas outras características muito importantes. Segundo o filósofo, uma delas é a gênese, isto é, todo dispositivo tem um ponto de partida, não é obra do nada, do acaso. Outra marca é que ele estará sempre associado com respostas às emergências individuais e sociais que surgem, ou dito de outro modo, ele entra em cena para anular dúvidas, reforçar teses, garantir a sensação de segurança. Convocar os dispositivos em casos de emergência é uma ação estratégica nas relações de poder porque eles podem auxiliar na organização e no conduzir do indivíduo e/ou dos coletivos conforme os interesses dos grupos sociais majoritários. Outra característica importante destacada por Foucault XXXVI é que todos os elementos do dispositivo (discursos, instituições, organizações, leis, etc) estabelecem uma rede entre si e atuam num campo de possibilidades, isto é, sem as garantias de sucesso de determinada proposição.

Deleuze, referenciando-se em Foucault, utiliza-se da metáfora do "novelo ou meada, um conjunto multilinear" para melhor caracterizar à ideia de dispositivo. Esse filósofo argumenta que o dispositivo é composto por uma série de linhas múltiplas de força e que se movimentam 


\section{JOSÉ CRISTIAN GÓES}

incessantemente. Elas tomam as mais variadas e incertas direções, o que vai garantir uma instabilidade central no dispositivo. Deleuze argumenta que o dispositivo, em sua movimentação, apresenta curvas de enunciação e de visibilidade, ou seja, faz falar e faz ver. No entanto, segundo Deleuze, em razão das tensões de forças no dispositivo, alguma linhas de forças podem ser caracterizadas como linhas de fuga e que, de alguma maneira, vão buscar romper uma espécie de estrutura desse novelo, configurando-se em fissuras e rupturas XXXVII.

Relembremos que, enquanto um fenômeno em disputa, as identidades tendem também à fixação, imutabilidade, sensação de naturalidade, o que pode ser resultado da ação das linhas de força majoritárias que buscam uma identidade fixa e perpetua. No entanto, isso parece ser tarefa impossível porque as identidades se dão em amplo processo relacional, de construção e desconstrução, de disputa de sentidos e significações, em razão de estratégias e das forças que atuam nelas. Bauman XXXVIII lembra que, como as identidades não foram naturalmente gestadas na experiência humana, elas carregam "muita coerção e convencimento para se consolidar e se caracterizar numa realidade". Dessa forma, "devemos pensar as identidades como um dispositivo discursivo porque são atravessadas por profundas divisões e diferenças”, como diz Hall XXXIX [grifo do autor].

Em razão dessas considerações, entendemos que as identidades, de modo especial às coletivas, a exemplo das nacionais, constituem-se como dispositivo à medida que formam, seguindo à formulação Foucault, esse conjunto heterogêneo de vários elementos que vão abarcar uma série de discursos, a exemplo das memórias e dos esquecimentos nacionais, os mitos fundadores, a existência de inimigos e de heróis. Esses discursos vão definir grande parte de nossas pertenças e, principalmente, marcar as nossas imaginárias diferenças para o outro, para o estrangeiro. Esse dispositivo, segundo Foucault, contempla instituições materiais e imateriais, que no caso das identidades podem ser as ideias de povo, de nação, a própria língua materna, os demais símbolos nacionais, como as cores e as bandeiras.

Como vimos em Foucault, o dispositivo também guarda as organizações arquitetônicas e, observando-se as identidades, podemos nomear os inúmeros monumentos nacionais, a exemplo do Cristo Redentor no Rio de Janeiro, e uma série de outras paisagens que falam de nossa identificação com o país. Esse dispositivo ainda tem as leis que, no caso das identidades pode ser a própria Constituição Federal, que rege a todos, e tem um papel de pertença central de delimitação nacional. Há ainda no dispositivo os enunciados científicos e morais, aos quais podemos associar à própria ideia fabular do que é o ser brasileiro? Há um ser imaginário visto como trabalhador e resistente, alegre, que gosta de futebol e de samba, que recebe bem, etc.

Aqui já estamos tratando do dispositivo identitário e podemos perceber ele é composto por várias estratégias políticas, econômicas, culturais, sociais, religiosas. Por isso, está inscrito diretamente nas tramas do poder, nas disputas, nas relações de força. As identidades, nessas condições, constituem-se em dispositivo porque são acionadas em emergências que serão respondidas. Os exemplos são muitos. Na Europa, vários governos e grupos organizados vêm usando com bastante clareza o dispositivo identitário em razão da crise imigratória que envolve países pobres e em guerra fora daquele continente. São fomentados os mais odientos discursos nacionalistas e que atravessam os mais variados segmentos sociais, como escolas, igrejas, artes, 


\section{JOSÉ CRISTIAN GÓES}

mídia, resultando em discursos nacionais, totalitários e xenófobos contra o outro. Esse é um processo de poder, de clara ação identitária de força que busca ter uma fala única, isto é, que faz falar e ver as fronteiras, e que impõem uma série de silenciamentos.

No Brasil, temos apelos identitários de empresas e do governo que transforma a nação na "pátria de chuteiras", por exemplo, num apelo dirigido à população para um pacto de união nacional em torno da seleção de futebol que disputava a Copa do Mundo de 2014. Tem-se aí uma nítida ilustração indicativa de uma emergência onde o dispositivo identitário se revela fundamental. Nesses apelos, ao reafirmar o brasileiro como um povo pacífico, cordial, alegre, que "tem a chuteira nos pés" parece reduzir e desviar, entre outros interesses, às críticas aos males sociais que afetam a maioria da população. Nessa ilustração, atravessam o dispositivo uma série de linhas de força do governo, do estado, da política, da economia, do esporte. Mais recentemente, nas manifestações contra a presidenta Dilma e o seu governo, grupos privados e organizados, partidos políticos, membros do Judiciário usam a bandeira nacional e as cores verde e amarela como dispositivo identitário de pertença e marcando uma forte e odienta diferença à cor vermelha, que representaria do partido da presidenta.

Lembremos que os processos identitários, em regimes democráticos, tendem sempre a certo acordo. A nacionalidade brasileira, por exemplo, é resultado de consenso, construído em pequenas e grandes mediações sociais na escola, na família, no trabalho, na mídia, na igreja etc. No entanto, existem discordâncias não visíveis na superfície dos acordos pacificados. Elas aparecem em certos silenciamentos, mas podem surgir no processo como falhas, como lapsos. Retomemos Foucault XL quando ele diz que "dito e o não dito são elementos do dispositivo".

Assim sendo, nas identidades, esse fenômeno social discursivo imerso em disputas, terão apenas alguns aspectos centrais, supostamente consensuais, ganhando visibilidade, mas eles serão fundamentais para marcar o campo da pertença e o da diferença. No entanto, quando as linhas de forças institucionais se impõem e iluminam uma parte, ganhando a superfície, acaba por produzir sombras e o silenciamento de outras, para aonde vai o que Foucault chamou de não-dito do dispositivo.

Em razão de curvas de visibilidade e de enunciação inferimos que existe aí um regime de seleção, isto é, a ação de poder selecionar poucas ocorrências diante de uma infinidade e, assim, enunciar acontecimentos sínteses e organizativos que atendem aos interesses políticos e identitários, no entanto, os eventos silenciados nesse processo não deixam de existir, e podem irromper a qualquer momento, a depender do jogo de forças. Selecionar é ação que implica escolher, separar e, ao mesmo tempo, descartar, excluir, ou seja, há aqui uma rede de intencionalidades que emerge das e nas relações, em disputas assimétricas, com várias linhas de força entrecruzando-se.

Como estamos em fluxo instável, enunciações e visibilidades também não são fixas. Quando as correlações de forças são alteradas, o que era visível pode passar à sombra. Uma observação necessária é que esse ambiente de silêncio, de sombra, de não-dito nas relações também pode ser resultado do seu inverso, ou seja, do excesso de luzes, do encandear desviante. A intensidade proposital de enunciações e de visibilidades, isto é, o bombardeio de luzes provoca um programado cegar. Assim, não é apenas sombra, silenciamento, ocultação, mas 


\section{JOSÉ CRISTIAN GÓES}

enunciações intensas e desviantes podem causar, estrategicamente, uma invisibilização, constituindo-se o que podemos chamar de simulacro do visível.

\section{Considerações finais}

O exercício que realizamos nesse texto nos encaminha para algumas pontuações que objetivam contribuir numa discussão ainda em aberta, porém que muitas vezes é rápida sobre as identidades.

Vimos que através da perspectiva dos Estudos Culturais, as identidades são percebidas como uma construção social móvel, "sob rasura", instável, problematizando concepções que ainda as enxergam como algo natural, fixo, herdado, estável. Com o advento das teorias globalizantes, as formulações dos Estudos Culturais sobre as identidades ganham fôlego, porque ficou caracterizada essa fluidez, ou seja, elas se confirmam como processo, um trânsito, movimento. A globalização faz crê na consolidação do cidadão-mundo, sem amarras identitárias, vivendo numa "aldeia global".

No entanto, com a globalização, as "velhas" identidades não desapareceram. Como a perda da sensação de segurança identitária, ocorre um processo inverso, de busca e "retorno" às identidades imaginariamente fixas como amparo social. Com a promessa de um mundo global para todos, as periferias rumam aos centros e percebem o engano do mundo único. Assim, de um lado, há o reforço das identidades "fixas", com ênfase no econômico, dos mais ricos que reacendem fronteiras e políticas nacionalistas e xenófobas como forma de proteção contra os mais pobres. De outro, busca-se no argumento das identidades por pertencimento, com ênfase no cultural e no ético-religioso, uma certa unidade dos excluídos, até como forma de reação às promessas de um mundo único para todos.

Michel Foucault vai contribuir com esse debate na medida em que chama atenção que os fenômenos sociais são entrecortados por relações de poder. Nesse sentido, as identidades são constituídas por essas disputas, por forças, por tensões que buscam fixar identidades para atender as lógicas do poder. A contribuição de Foucault é maior para pensar as identidades na medida em que recorremos à ideia de dispositivo. Assim, podemos sugerir que a identidade não é um fim em si, mas um meio, um mecanismo, um dispositivo que dispara processos de pertenças e, principalmente, de diferenças, e para isso usa uma série de elementos, como discursos, instituições materiais e imateriais, organizações arquitetônicas, leis, enunciados científicos e morais.

Esse conjunto (dispositivo identitário) é acionado por forças sociais em disputa para responder, principalmente, as emergências que surgem, no sentido de reforçar e retomar uma imaginária identidade fixa e que interessa a esquemas de poder, configurando um nós, mas especialmente estabelecendo e opondo o outro a ser combatido, excluído. Porém, em razão das condições instáveis das identidades, esse dispositivo, ao mesmo tempo em que ilumina uma direção, também ofusca outras. Relembremos que Foucault assegura que "o dito e o não dito são elementos do dispositivo". Aqui propomos um salto reflexivo, ou seja, perceber que esse lugar supostamente silenciado, de sombras, "não dito" no dispositivo está aberto, é criativo, inclusive para construir as resistências e fissuras nos processo identitários. O dispositivo, assim, faz vez 


\section{JOSÉ CRISTIAN GÓES}

um ambiente instável e mobilizado por uma série de força de poder para tentar enquadrar, domesticar, fixar uma identidade, porém esse é um processo composto de "não-ditos" que forçam os quadros supostamente estabilizados para fissuras e rupturas.

\section{Notas}

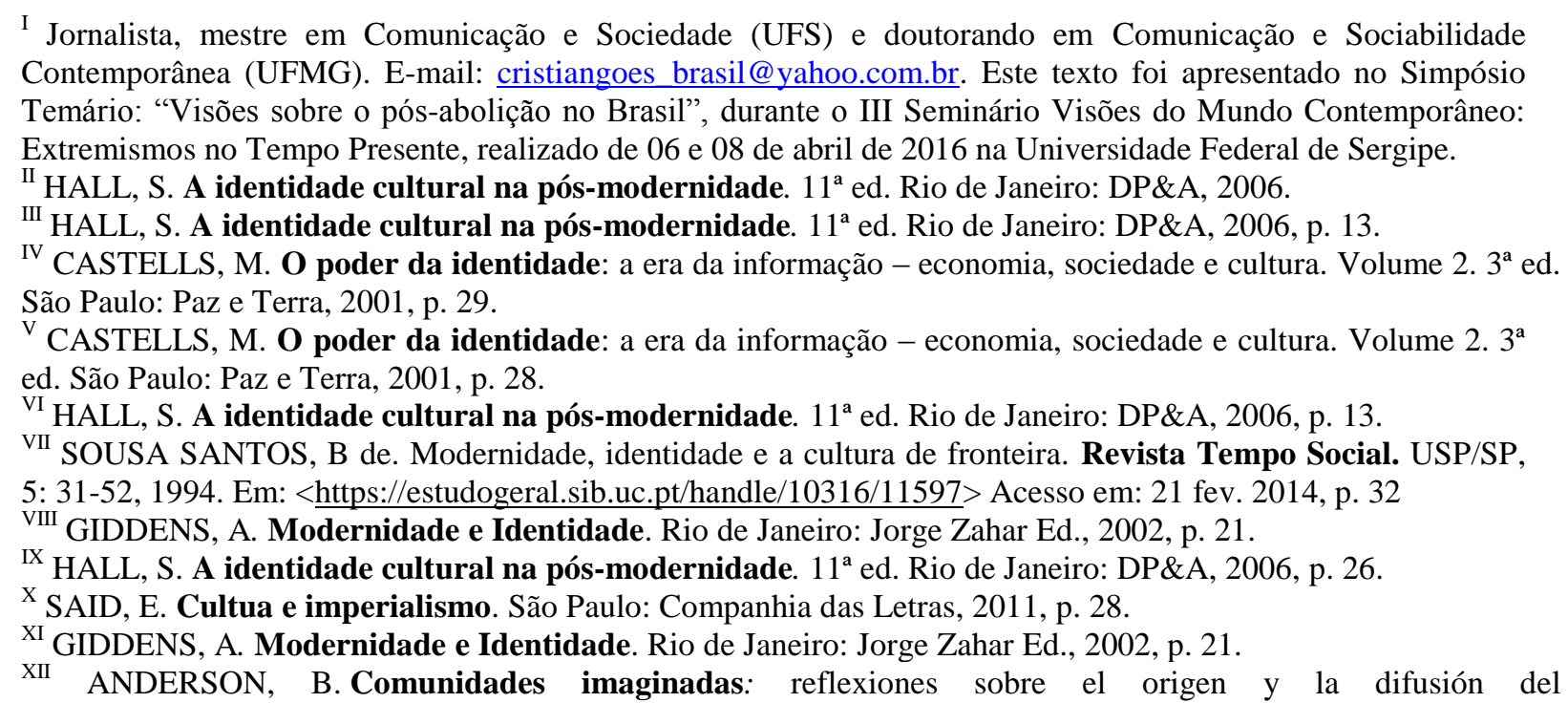
nacionalismo. México: FCE, 1993.

XIII HOBSBAWM, E. Nações e nacionalismos desde 1780: programa, mito e realidade. Rio de Janeiro: Paz e Terra, 1990, p. 20.

XIV BALIBAR, E. La forma nación: historia e ideología. In: BALIBAR, E; WALLERSTEIN, I. Raza, Nación y Clase. Madri: IEPALA, 1991, p. 135-167.

XV BALIBAR, E. La forma nación: historia e ideología. In: BALIBAR, E; WALLERSTEIN, I. Raza, Nación y Clase. Madri: IEPALA, 1991, p. 136.

${ }^{\mathrm{XVI}}$ SAID, E. Cultua e imperialismo. São Paulo: Companhia das Letras, 2011, p. 480.

${ }^{\text {XVII }}$ SOUSA SANTOS, B de. Modernidade, identidade e a cultura de fronteira. Revista Tempo Social. USP/SP, 5: 31-52, 1994. Em: <https://estudogeral.sib.uc.pt/handle/10316/11597> Acesso em: 21 fev. 2014, p. 31

XVIII BAUMAN, Z. Identidade. Rio de Janeiro: Jorge Zahar Ed., 2005, p. 17.

XIX HALL, S. A identidade cultural na pós-modernidade. 11ª ed. Rio de Janeiro: DP\&A, 2006, p. 13.

XX BHABHA, H. O Local da cultura. Belo Horizonte: Editora UFMG, 1998, p. 85.

XXI BHABHA, H. O Local da cultura. Belo Horizonte: Editora UFMG, 1998, p. 79.

XXII HALL, S. A identidade cultural na pós-modernidade. $11^{\mathrm{a}}$ ed. Rio de Janeiro: DP\&A, 2006, p. 81.

XXIII HALL, S. A identidade cultural na pós-modernidade. $11^{\mathrm{a}}$ ed. Rio de Janeiro: DP\&A, 2006, p. 13.

XXIV BAUMAN, Z. Identidade. Rio de Janeiro: Jorge Zahar Ed., 2005.

XXV SAID, E. Cultua e imperialismo. São Paulo: Companhia das Letras, 2011.

XXVI SAID, E. Cultua e imperialismo. São Paulo: Companhia das Letras, 2011, p. 28.

XXVII BAUMAN, Z. Identidade. Rio de Janeiro: Jorge Zahar Ed., 2005, p. 83.

XXVIII SANTOS, M. Por uma outra globalização: do pensamento único à consciência universal. 2. ed. Rio de Janeiro: Record, 2000.

XXIX SANTOS, M. Por uma outra globalização: do pensamento único à consciência universal. 2. ed. Rio de Janeiro: Record, 2000, p. 85.

XXX SANTOS, M. Por uma outra globalização: do pensamento único à consciência universal. 2. ed. Rio de Janeiro: Record, 2000, p. 75.

XXXI SANTOS, M. Por uma outra globalização: do pensamento único à consciência universal. 2. ed. Rio de Janeiro: Record, 2000, p. 70.

XXXII SOUSA SANTOS, B de. Modernidade, identidade e a cultura de fronteira. Revista Tempo Social. USP/SP, 5: 31-52, 1994. Em: <https://estudogeral.sib.uc.pt/handle/10316/11597> Acesso em: 21 fev. 2014, p. 50 
XXXIII FOUCAULT, M. Microfísica do poder. Rio de Janeiro: Graal, 1979, p. 244.

XXXIV FOUCAULT, M. História da Sexualidade. Rio de Janeiro: Graal, 1988.

${ }^{X X X v}$ FOUCAULT, M. História da Sexualidade. Rio de Janeiro: Graal, 1988, p. 83.

${ }^{x x x V I}$ FOUCAULT, M. História da Sexualidade. Rio de Janeiro: Graal, 1988.

xxxvII DELEUZE, G. ¿Que és un dispositivo? In: BALBIER, E. et al. Michel Foucault, filósofo. Barcelona: Gedisa, 1990.

XXXVIII BAUMAN, Z. Identidade. Rio de Janeiro: Jorge Zahar Ed., 2005, p. 26.

XXXIX HALL, S. A identidade cultural na pós-modernidade. $11^{a}$ ed. Rio de Janeiro: DP\&A, 2006, p. 61/62.

${ }^{\mathrm{XL}}$ FOUCAULT, M. Microfísica do poder. Rio de Janeiro: Graal, 1979, p. 244.

\section{Referências Bibliográficas}

ANDERSON, B. Comunidades imaginadas: reflexiones sobre el origen y la difusión del nacionalismo. México: FCE, 1993.

BALIBAR, E. La forma nación: historia e ideología. In: BALIBAR, E; WALLERSTEIN, I. Raza, Nación y Clase. Madri: IEPALA, 1991, p. 135-167.

BAUMAN, Z. Identidade. Rio de Janeiro: Jorge Zahar Ed., 2005.

BHABHA, H. O Local da cultura. Belo Horizonte: Editora UFMG, 1998.

CASTELLS, M. O poder da identidade: a era da informação - economia, sociedade e cultura. Volume 2. $3^{\text {a }}$ ed. São Paulo: Paz e Terra, 2001.

DELEUZE, G. ¿Que és un dispositivo? In: BALBIER, E. et al. Michel Foucault, filósofo. Barcelona: Gedisa, 1990.

FOUCAULT, M. História da Sexualidade. Rio de Janeiro: Graal, 1988.

Microfísica do poder. Rio de Janeiro: Graal, 1979.

GIDDENS, A. Modernidade e Identidade. Rio de Janeiro: Jorge Zahar Ed., 2002.

HALL, S. A identidade cultural na pós-modernidade. 11ª ed. Rio de Janeiro: DP\&A, 2006.

HOBSBAWM, E. Nações e nacionalismos desde 1780: programa, mito e realidade. Rio de Janeiro: Paz e Terra, 1990.

SAID, E. Cultua e imperialismo. São Paulo: Companhia das Letras, 2011.

SANTOS, M. Por uma outra globalização: do pensamento único à consciência universal. 2. ed. Rio de Janeiro: Record, 2000.

SOUSA SANTOS, B de. Modernidade, identidade e a cultura de fronteira. Revista Tempo Social. USP/SP, 5: 31-52, 1994. Em: <https://estudogeral.sib.uc.pt/handle/10316/11597> Acessado em: 21 fev. 2014. 